\title{
EXPERIMENTAL INVESTIGATION ON THE EFFECTS OF ETHYL ACETO ACETATE (EAA), DIETHYL CARBONATE (DEC) AND DIETHYLENE GLYCOL (DEG) BLENDED WITH FOSSIL FUEL AS OXYGENATED ADDITIVES IN DI DIESEL ENGINES
}

\author{
Parthasarathi. $\mathbf{B}^{1}$ And Sundarapandian. $S^{2}$ \\ ${ }^{1}$ Associate Professor, Mechanical engineering, ACEW, TN, India. \\ ${ }^{2}$ Professor, Automobile engineering, EEC, Chennai-600 089, TN, India. \\ Mail id; profbparthasarathi@gmail.com
}

\begin{abstract}
In this paper, the performance and emission characteristics were investigated using oxygenates chosen blended with conventional fuel as enriched fuel additive with pure diesel in Direct Injection (DI), single cylinder CI engine. The observations of the experimental analysis have been analyzed by the characteristic's curves drawn for various engine parameters using MATLAB 2010 software. A MATLAB 2010 code was developed for analyzing the recorded observations for calculating the main engine performance parameters. The assessment of the experimental results showed that the above oxygenated additives have more beneficial impact on soot and NO emissions when compared with the results of other additives.
\end{abstract}

Keywords: Oxygenated additives, CI Engines, Emission, Direct injection, Energy Consumption, Engine Performance.

\section{INTRODUCTION}

The lesser fuel consumption, comparatively longer life extent, minor repairs and great consistency results the diesel engine in its wide-ranging use in transportation, power production and many more industrial and agricultural applications. Generally, diesel engines are efficient prime movers for heavy duty vehicles. So many automotive and research institutions considered this for their main prime movers of vehicles. But it is the notable contributor of exhaust emissions, which leads to serious health issues. Therefore, reducing the emission from diesel engines is very essential one and it is one of the main issues today. Significant research has been carried out on the usage of diesel engines to light duty vehicles and small engines. The major problems facing the diesel engines' developments are managing and controlling the diesel knock, idle stability, engine speed hunting and controlling of nitric oxide emission.

The raise in usage of vehicles along with other factors such as global fuel requirement, depletion of existing petroleum resources and more stringent emission standards results in better innovation for all types of engines. It is very tough to provide solution for the problems like high vehicle fuel consumption, high emission and performances challenges. The demand for diesel engines continuously grows rapidly worldwide due to their high thermal efficiency, high compression ratio and lean operating conditions. In this trend, there is an increased urgency to find ways to improve fuel economy by controlling the emissions.

The research work is going on to develop after treatment and in-cylinder control processes to reduce the emission for few decades. In this research work, paying attention on the use of

Received OCT 30, 2020 www.dynamicpublishers.com; www.dynamicpublishers.org;
ISSN1056-2176(Print); ISSN 2693-5295 (online) $\$ 15.00$ CDynamic Publishers, Inc. https://doi.org/10.46719/dsa202130.11.04 
oxygenates had chosen blended with the conventional fuel to increase in fuel efficiency while reducing harmful greenhouse gas emissions and the health-threatening chemicals such as NOx and particulate matter emissions from CI engines.

M. Venkatraman, Abhijetdey, Ajay kumar and Deepak kumar (2016) [5] analyzed various blends of oxygenates $(10 \%, 20 \%, 30 \%$ 2-EEA, 2-BE, DBM) and the blend 30\% 2-EEA have higher BTE than other blends. The Rate of Heat Release (ROHR) is also lesser than that of diesel.S. Singh, A. Kumar, S. K. Mahla and G. S. Batth (2013) [4] used Dimethyl carbonate (DMC) and Dibutyl Maleate (DBM) are was used with diesel in different blends for all load ranges at constant engine speed 1500 RPM. It results the reduction of smoke content by $35 \%$ at high loads using DMC20 blend, the oxygen content in the discharge increases by $39 \%$ with DBM15, the amount of reduction in HC and CO is $19 \%$ and $21 \%$. Diesel with $15 \%$ DMC and DBM is the best proportion for reducing the smoke and $\mathrm{CO}$ emissions without affecting the performance of the engine.AbhijitKulkarni, GauriSalvi, MandarGophane and B. Ashok, (2013) [3] used diesel and diethylene glycol dimethyl ether (diglyme) in a single cylinder vertical air cooled diesel engine at a constant speed of $1500 \mathrm{rpm}$ under variable load conditions and the tests indicated significant reductions in emission levels of $\mathrm{CO}, \mathrm{HC}$ and smoke but increase in the level of NOx.Kumaresn, MDevaradjane, G (2012) [2] studied the performance, and emission characteristics of diesel and DEC blend of $10 \%$ by volume in a DI, single cylinder dieselengine using two-springs split injection and observed that at an injection timings of $27^{\circ}$ before top dead center (BTDC) the brake thermal efficiency (BTE) is found as $29.3 \%$, NOx as $1.32 \mathrm{~g} / \mathrm{kWh}$ and smoke level as $36 \%$ opacity.

Y Wang et al (2008) [14] studied about the Oxygenating additive for reducing the emission of Diesel engine. They concluded that Oxygenated diesel fuel blends have a potential to reduce the emission of particulate matter (PM) and to be a propersubstitute to conventional fuel. This paper deals a new type of oxygenate additive, ethylene glycol mono acetate (EGM), and its effects on the characteristics of performance and emission of CI engines.A Upatnieks et al (2004) [6] studied the investigation of the relationship between DI Diesel combustion processes and Engineout soot using an Oxygenated Fuel. The relationship between combustion processes and engineout soot was investigated in an optically accessible DI diesel engine using di ethylene glycol diethyl ether (DGE) fuel, a viable diesel oxygenate. The high oxygen content of DGE enables the processwithout soot emissions at high loads than with a conventional fuel.Natarajan, M., Frame, E., Naegeli, D., Asmus, T, Clark, W, Garbak, J, A. Manuel, D. González, Liney, E, Piel, W and Wallace, J. (2001) [1] studied about the Oxygenates for advanced petroleum based Diesel fuels (Screening and Selection Methodology for the Oxygenates) and they concluded that according to the screening criteria, eight oxygenated compounds such as Methylal, Di-butyl maleate, Tributyrin, Di-ethyl adipate, 2-Ethoxy ethyl acetate, 2-Ethoxy ethyl ether, Tri-propylene glycol mono-methyl ether, and Di-propylene glycol ether mono-methyl ether were most suitable for blending with diesel. These will be eligible for engine testing and emission performance evaluation. 


\section{PROPOSED WORK}

\subsection{Problem definition}

After a systematic and critical comparative study of the previously published articles, the problem undertaken for examination is to carry out experimental investigation of the performance and emission characteristics of diesel and diesel-oxygenated additives blends namely Di Ethyl Carbonate, Ethyl Aceto Acetate, Di Ethylene Glycol, in proportions of 5\%, 7\% and 10\% by volume in a direct injection, single cylinder diesel engine. The results were compared to identify the best blend and the best proportions of the blends with diesel for best performance and significantly reduced emission.

Many research works are going on to achieve better engine performance, using oxygenates as additives which is optimally mixed with diesel resulting in low emissions and thereby reducing the fossil fuel consumption. The recent revolutionary encroachment in oxygenates made the fuel researchers to search for suitable additives, to further enhance the engine performance and also to reduce the emissions. In this way, an attempt is made in the present research to study the engine performance and emission characteristics of the nine modified fuels prepared, and a comparison is made with pure diesel in Direct Injection (DI), single cylinder CI engine. The observations of the experimental analysis have been analyzed by the characteristics curves drawn for various engine parameters using MATLAB 2010 software. A MATLAB 2010 code was developed for analyzing the recorded observations for calculating the main engine performance parameters.

\subsection{Objectives of the Present Investigation}

The objectives of the present investigation are detailed below:

To sort out and compare different promising oxygenated additives with standards based on various parameters like physical and chemical properties, performance, emission, availability, practicability etc., Ethyl Aceto Acetate (EAA), Diethyl Carbonate (DEC) and Diethylene Glycol (DEG) are the promising fuel additives to reduce emission in diesel engine, due to their high oxygen content, $36.9,40.36$, and $45.2 \mathrm{wt} \%$ respectively.

The investigational works have been conducted with regard to engine's output performance running on pure diesel will be compared to its performance while the operation on diesel with oxygenated additives. To estimate the engine's performance on the significant parameters which includes brake thermal efficiency, brake specific fuel consumption and exhaust gas temperature.

To conduct diesel engine emission test on chosen oxygenated additive blends and compare with diesel fuel. The calculated emission includes carbon monoxide (CO) emissions, unburned hydro-carbon (HC) emissions, Nitrogen oxide (NO) and smoke density. The investigation has been 
performed to combine fuel property characterization and instantaneous engine performance and emission tests with fuel blends taking into account the tactical issues to its practicability.

\section{OXYGENATES AND BLENDS}

\subsection{DIESEL OXYGENATES}

Oxygenates are considered as diesel fuel components mainly due to their capability to reduce particulate matter emission (PM). When based on renewable feedstocks, oxygenates can also tackle with the challenges of climate change and energy security. A number of different oxygenates, for example alcohols, ethers, esters, and carbonates, have been explored as diesel fuel components. The general structure oftheprominent oxygenates are tabulated inTable 1. Many studies have covered a comprehensive set of oxygenates, e.g. Pecci et al. (1991) reviewed 80 oxygenates, Natarajan et al. (2001) considered 71 oxygenates and Delfort et al. (2002) studied 18 oxygenates. In addition, numerous studies have focused on specific oxygenate groups (Nylund et al. 2005).

Table 1. The general structure of Oxygenates

\begin{tabular}{|l|l|}
\hline R-OH & Alcohols \\
\hline R-O-R & Ethers \\
\hline R-O-R-O-R & Glycol ethers \\
\hline R-O-C-O-R $(=O)-O-R$ & Acetals \\
\hline R-O-C $=$ O)-O-R & Esters \\
\hline R hydrocarbon chain; C carbon; O oxygen \\
\hline
\end{tabular}

From the comparative study, it was observed that the following three oxygenates are used for the experiment based on the properties of diesel and oxygenates and also considering many aspects like, cost, oxygen content, flash point, solubility, availability, toxicity, lubricity, and biodegradability. The chemical structure of the diesel oxygenates chosen was listed in Table 2.

1. Ethyl Aceto Acetate (EAA)

2. Diethyl Carbonate (DEC)

3. Diethylene Glycol (DEG) 
Table 2.Chemical structure of oxygenates chosen

\begin{tabular}{|c|c|c|c|}
\hline $\begin{array}{c}\text { Sl. } \\
\text { No }\end{array}$ & Name of the Oxygenate & $\begin{array}{c}\text { Molecular } \\
\text { Formula }\end{array}$ & Chemical Structure \\
\hline 1 & Ethyl Aceto acetate & $\mathrm{C}_{6} \mathrm{H}_{10} \mathrm{O}_{3}$ & $\mathrm{CH}_{3}[\mathrm{C}=\mathrm{O}] \mathrm{CH}_{2}\left[\mathrm{C}=\mathrm{O}^{-} \mathrm{OCH}_{2} \mathrm{CH}_{3}\right.$ \\
\hline 2 & Diethyl carbonate & $\mathrm{C}_{5} \mathrm{H}_{10} \mathrm{O}_{3}$ & $\mathrm{CH}_{3} \mathrm{CH}_{2} \mathrm{O}[\mathrm{C}=\mathrm{O}] \mathrm{OCH}_{2} \mathrm{CH}_{3}$ \\
\hline 3 & Diethylene glycol & $\mathrm{C}_{4} \mathrm{H}_{10} \mathrm{O}_{3}$ & $\mathrm{HOCH}_{2} \mathrm{CH}_{2} \mathrm{OCH}_{2} \mathrm{CH}_{2} \mathrm{OH}$ \\
& & & \\
\hline
\end{tabular}

The selected oxygenates are blended with diesel fuel in proportion of 5\%, $7 \%$ and $10 \%$ by volume and experimental study is conducted in a single cylinder naturally aspirated direct injection diesel engine. The blending levels are restricted due to reduction of calorific value, corrosion and lubricity problems. The combustibility of a diesel fuel in diesel engines is characterized by its Cetane number, which is a measure of its ability to undergo compression ignition under standard test conditions. Fuels with a higher Cetane number more readily ignite engines.It was concluded that the suitability of the blends was ascertained after critical analysis of the properties of diesel, oxygenates and oxygenated diesel blends as well as laboratory tests. However the oxygenates have the following limitations.

1. Oxygenates are 10 to 25 times costlier than diesel.

2. Heating valve is lower than diesel.

3. Corrosive at when blending levels exceeds $20 \%$.

There are some of the factors that limit the application of oxygenates in CI engines. The blending levels are chosen to have sufficient oxygen content for smoke reduction and at the same time without much loss of heating values for the blends

\subsection{DIESEL - OXYGENATE BLENDS}

oxygenated additives used for the experiment based on the properties of diesel and oxygenates and also considering other aspects like, cost, oxygen content, flash point, solubility, availability, toxicity, lubricity, and biodegradability. The comparison of the properties of diesel and oxygenates chosen was listed in Table 3.

Table 3Properties of diesel and oxygenates 


\begin{tabular}{|c|c|c|c|c|}
\hline Properties & Diesel & DEC & DEG & EAA \\
\hline Density g/cc & 0.826 & 0.980 & 1.1184 & 1.021 \\
\hline $\mathrm{O}_{2}(\mathrm{Wt} \%)$ & - & 40.36 & 45.2 & 36.9 \\
\hline Cetane Number & 45 & 58 & 49 & 46 \\
\hline Boiling Point ${ }^{\circ} \mathrm{C}$ & $199 / 317$ & 126 & 245 & 181 \\
\hline Flash Point ${ }^{\circ} \mathrm{C}$ & 50 & 25 & 143 & 70 \\
\hline State & clear liquid & clear liquid & clear liquid & clear liquid \\
\hline
\end{tabular}

The oxygenates chosen are blended with diesel in fraction of 5\%,7\%, and $10 \%$ by volume and experimental investigation is conducted in a single cylinder naturally aspirated DI, single cylinder diesel engine. The combination levels are restricted due to reduction of calorific value, corrosion and lubricity problems.

\section{METHODS}

This paper deals the experimental investigation and is distinctively different from others by choosing the best oxygenates from the available oxygenates and tried ten different proportions including pure diesel for every parameters and the performance and emission characteristics were investigated in Direct Injection (DI), single cylinder CI engine. The observations of the experimental analysis have been analyzed by the characteristics curves drawn using MATLAB software.

\subsection{DESCRIPTION OF ENGINE}

Naturally aspirated engine was selected for evaluation for two specific reasons. First, a naturally aspirated engine represents a larger population of engines sold in agricultural and construction equipment for the last 50 more years. Secondly, it is more sensitive due to longer ignition delays and lower pressure injection equipment. The kirlosker (speedwell) engine is one of the widely used engines in agricultural, pump sets, farm machinery, transport-vehicles, small and medium scale commercial purposes. The engine can withstand higher pressures encountered during tests because of its rugged construction. Hence this engine is selected for the present work. The engine specificationsused for this investigation are tabulated in table 4 .

Table 4. Engine Specifications 


\begin{tabular}{|l|l|}
\hline Make & Kirloskar (Speedwell), Gujarat Forgings Limited \\
\hline Type & Vertical inline diesel engine, 4 stroke \\
\hline Speed & $1600 \mathrm{rpm}$ \\
\hline Bore x stroke & $80 \mathrm{~mm}$ x 110mm \\
\hline Compression ratio & $15.6: 1$ \\
\hline Rated brake power & $5.9 \mathrm{~kW}(8 \mathrm{hp})$ \\
\hline Fuel injection pump & MICO inline, with mechanical \\
\hline
\end{tabular}

The performance characteristics of the engine are evaluated in terms of Brake Thermal efficiency and Specific Fuel Consumption, emission characteristics in terms of smoke, Hydro Carbon, Carbon Monoxide, Carbon dioxide and Oxides of Nitrogen. The performance and emission characteristics are compared with diesel and different oxygenated additive diesel blends such as Di Ethyl Carbonate, Ethyl Aceto Acetate, Di Ethylene Glycol in the proportions of $5 \%, 7 \%$ and $10 \%$ by volume.

An experimental set up was made with necessary instrumentation to evaluate the performance, combustion and emission parameters of the diesel engine at different operating conditions. The layout of the investigational arrangement is shown in Figure 1. 


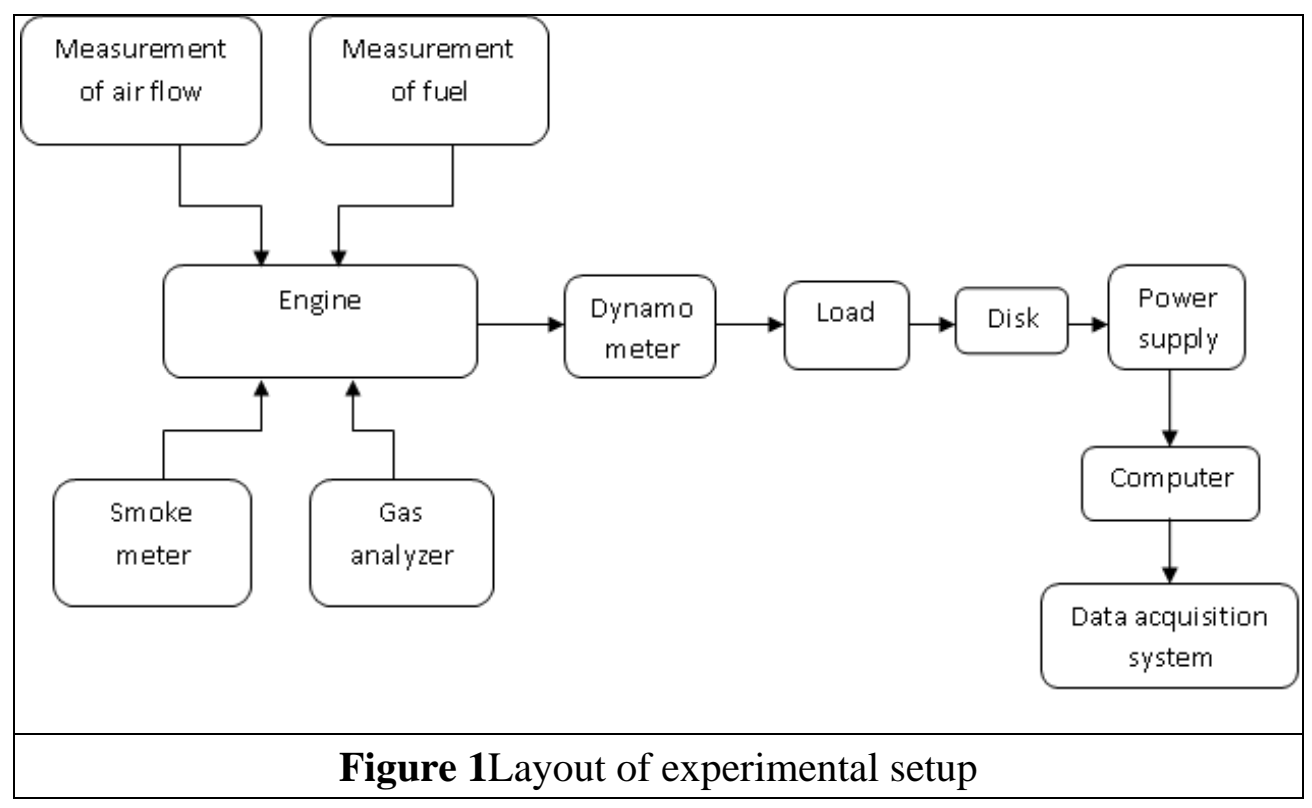

In the beginning, the engine was permitted to run with pure diesel at a constant speed of 1500rpm for 30 minutes to achieve thesteady state conditions at the lowest probable load. During this investigation, the temperature of lubricating oil and engine cooling water were kept constant to eradicate their influence on the findings. The speed of the engine was stabilized with injected fuel to attain the temperature of lubricating oil as $65^{\circ} \mathrm{C}$ and cooling water as $60^{\circ} \mathrm{C}$.

The exhaust gas analyzer and smoke meter is switched on quite early so that all its systems will get stabilized before the commencement of the experiment and the following observations were documented.

1. Time duration for $50 \mathrm{cc}$ of fuel consumption.

2. Measurement of smoke by AVL 437 smoke meter.

3. Measurement of $\mathrm{CO}, \mathrm{CO}_{2}, \mathrm{HC}, \mathrm{O}_{2}$ and $\mathrm{NOx}$ by Crypton 5 gas analyzer.

4. Measurement of Performance Characteristics (BTE and BSEC)

Tests were conducted from no load, 0.75, 1.5, 2.5, 3.5, 4, 4.71, $5.5 \mathrm{~kW}$ Brake Power (BP) output at a constant speed of $1500 \mathrm{rpm}$, with fuel injection pressure of $200 \mathrm{bar}$ and $60^{\circ} \mathrm{C}$ cooling water outlet temperature and the injection timing was $27^{\circ} \mathrm{bTDC}$ (spill).

\section{RESULTS AND DISCUSSION}

The experimental studies are conducted in a single cylinder naturally aspirated direct injection diesel engine using Diesel and Diesel-oxygenated blends of 5\%,7\% and $10 \%$ by volume. The engine is run at a constant speed of $1500 \mathrm{rpm}$. Adding Oxygenates to diesel fuel to reduce the engine emission without engine modification seems to be more attractive than others. Oxygenates also influence the ignition delay, the rapid combustion and the total 
combustion durations. The important results of the experimental work such as the performance, and emission parameter values are presented in the following sections.

\subsection{Comparison of Performance Characteristics}

\subsubsection{Brake thermal efficiency (BTE)}

The thermal efficiency is the ratio among the power output and the energy input through fuel injection, the latter being the product of the injected fuel mass flow rate and the lower heating value.This parameter is more appropriate than fuel consumption for comparing the performance of the different blends.

The brake thermal efficiency indicates the ability of the combustion system to accept the experimental fuel and provides comparable means of assessing how effectively the energy in the fuel was converted into mechanical output.

All the three oxygenates shows an increase in the brake thermal efficiency with increase in the percentage of oxygenates from 5, to 10 .The $10 \%$ blends of all oxygenates are observed to show higher brake thermal efficiency as the oxygen content in the blends increases with increasing percentage of the blend.

From the analysis of figure 2, it is concluded that $10 \%$ DEC blend is the best oxygenated blend compared to other percentage levels with respect to brake thermal efficiency. It is observed that, brake thermal efficiency (BTE) of Diesel-10\% DEC is about $31.1 \%$, thus an increase of $3.9 \%$ is observed. This is due to the presence of higher cetane number for the Diesel-10\% DEC blend compared with other oxygenates blends.

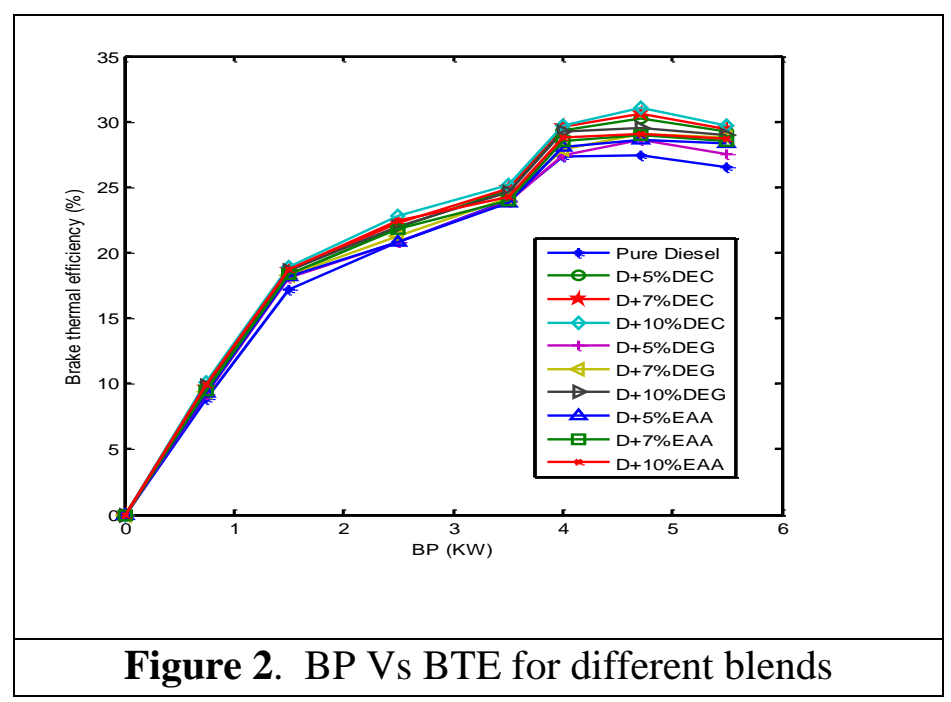

\subsubsection{Brake Specific Energy Consumption (BSEC)}


The specific fuel consumption (SFC) values of an engine are inversely proportional to its Brake Thermal Efficiency (BTE). The fuel blends mass flow rate is calculated from the respective measured volume flow rate value and the blend density. Since the comparison is made at the same load and speed which is translated in to the same engine power, the specific fuel consumption values are then directly proportional to fuel mass flow rate. However, to compare performance of different fuels and their blends with different calorific values, the more appropriate parameter will be the brake specific energy consumption (BSEC), which was used in the present study.

All the three oxygenates shows an decrease in the brake specific energy consumption with increase in the percentage of oxygenates from 5, to 10.The 10\% blends of all oxygenates are observed to show lower brake specific energy consumption as the oxygen content in the blends increases with increasing percentage of the blend which improves the degree of combustion. The performance of diesel oxygenated blend is so higher with the 10\%proportion of the DEC blends.

From the analysis of Figure 3, it is concluded that $10 \%$ DEC blend is the best oxygenated blend compared to other percentage levels with respect to brake specific energy consumption.It is observed that, the brake specific energy consumption of Diesel-10\% DEC is $12.1 \mathrm{MJ} / \mathrm{kWhr}$, thus saving $1.41 \mathrm{MJ} / \mathrm{kWhr}$.



\subsection{Comparison of Emission Parameters}

\subsubsection{Carbon monoxide emission}


Diesel engines always operate on the lean side of the stoichiometrics, therefore Carban monoxide emission from diesel engine is not much significant, but the local air/fuel ratio prevailing during droplet evoporation is important aspect in $\mathrm{CO}$ generation.

All the three oxygenates shows decrease in the $\mathrm{CO}$ emissions with increase in the percentage of oxygenates from 5, to 10 .The $10 \%$ blend of all oxygenates are observed to show lower CO emissions.From the analysis of figure 4,It is observed that the $\mathrm{CO}$ emission of diesel is 2.68 $\mathrm{g} / \mathrm{KWhr}$ and the Diesel-10\% DEC blend is $1.96 \mathrm{~g} / \mathrm{KWhr}$. Therefore it is concluded that the Diesel-10\% DEC blend is the best oxygenate blend compared to other with respect to CO emissions.

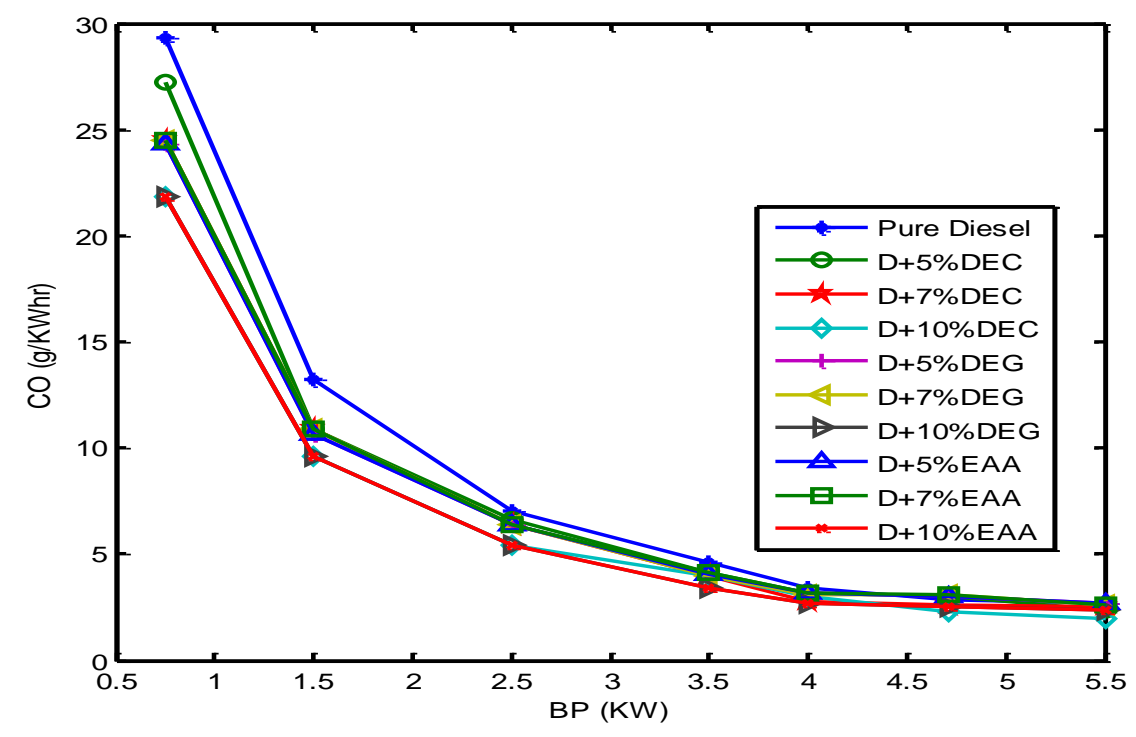

Figure 4. BP Vs CO for different blends

\subsubsection{Hydrocarbon emission}

Hydrocarbons (HC) are more appropriately organic emissions, are the consequence of incomplete combustion of the hydrocarbon fuel. The level of unburned hydrocarbon in the exhaust gases is generally specified in terms of the total hydrocarbon concentration expressed in ppmcarbon atoms. While total hydrocarbon emissions are a useful measure of combustion inefficiency, it is not necessarily a significant index of pollutant emissions. Fuel composition isnotably influence the composition and magnitude discharge of Hydro Carbons.

All the three oxygenates shows an decrease in the $\mathrm{HC}$ emissions with increase in the percentage of oxygenates from 5, to 10 .The $10 \%$ blends of all oxygenates are observed to show lower HC emissions with increasing percentage of the blend. The decrease in hydro carbon emissions is 
due to improvements of fuel burning as a result of acceleration of combustion process owing to the presence of oxygen inside the fuel molecule. The favoring part of oxygenated fuels is the reduction of incomplete combustion pollutant residuals because of reduced ignition delay with increased oxygen content.

From the analysis of figure 5, it is seen that the $\mathrm{HC}$ emission for diesel is $0.33 \mathrm{~g} / \mathrm{kWhr}$ and for $10 \%$ DEC blend is $0.3 \mathrm{~g} / \mathrm{kW} \mathrm{hr}$. It is concluded that $10 \% \mathrm{DEC}$ blend is the best oxygenated blend compared to other percentage levels with respect to $\mathrm{HC}$ emissions.

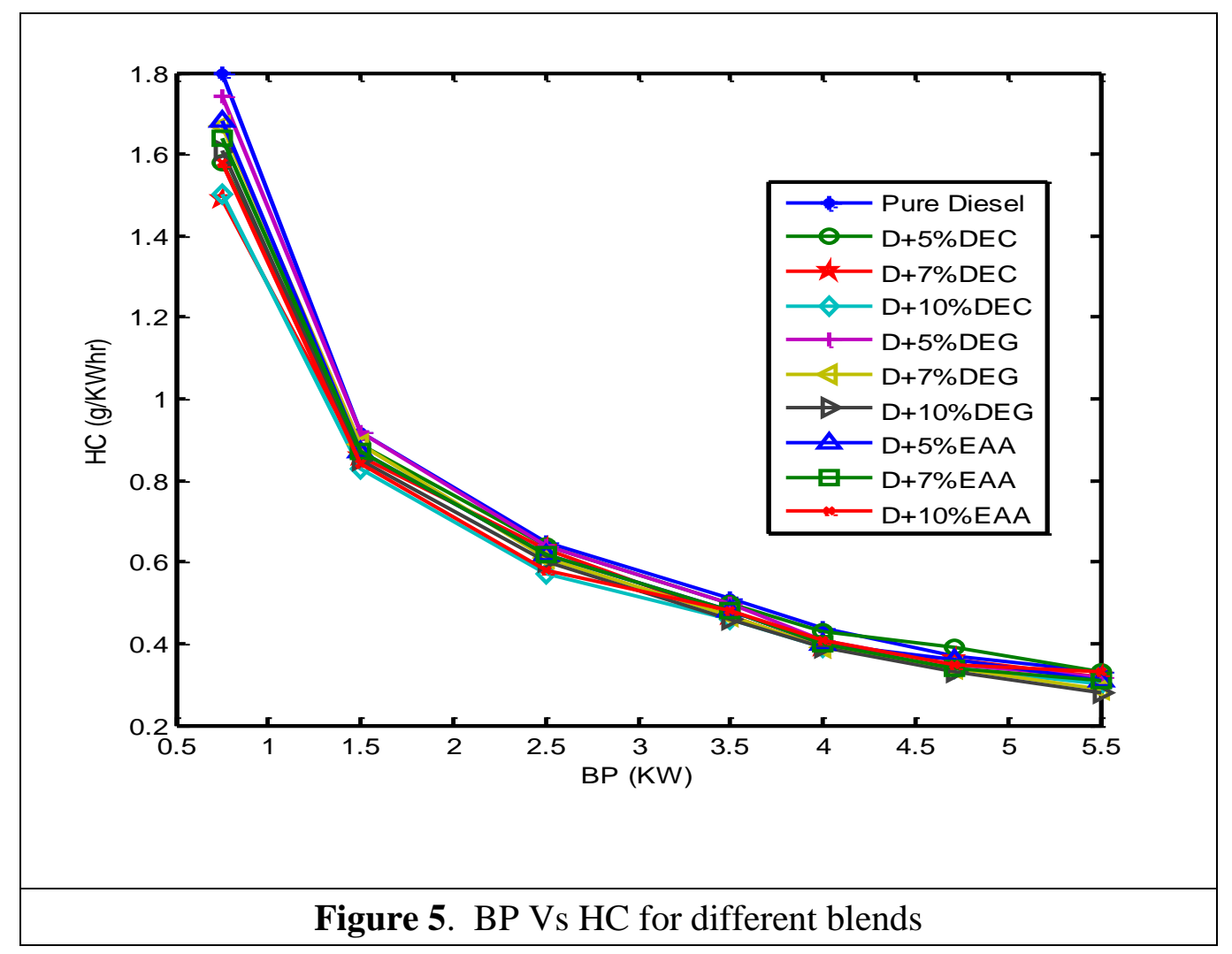

\subsubsection{NOx emission}

The effect of oxygenated fuel blends on NOx emission is very complex and is not conclusive. The cetane number,fuel density can influence NOx emissions.Local rich combustion and high tempareture are very important for NOx formation.

There is an increasing trend of NOx emission with increasing percentage of oxygenates due to effective combustion. An increase of NOx emissions with increasing oxygen content of the oxygenates is observed forall engine loads considered. The rate of NOx increase is lower at low oxygen content for $5 \%$ and higher for $10 \%$ blending. 
From the analysis of figure 6, it is observed that Diesel-10\% DEC blend emits higher NOx emissions but as the Diesel-10\% DEC blend gives good outcomes in the other parameters discussed previously it is concluded, Diesel-10\% DEC blend as the best alternative compared with other percentage levels regarding NOx emissions. For Diesel-10\% DEC blend the NOx emission is $393 \mathrm{ppm}$.

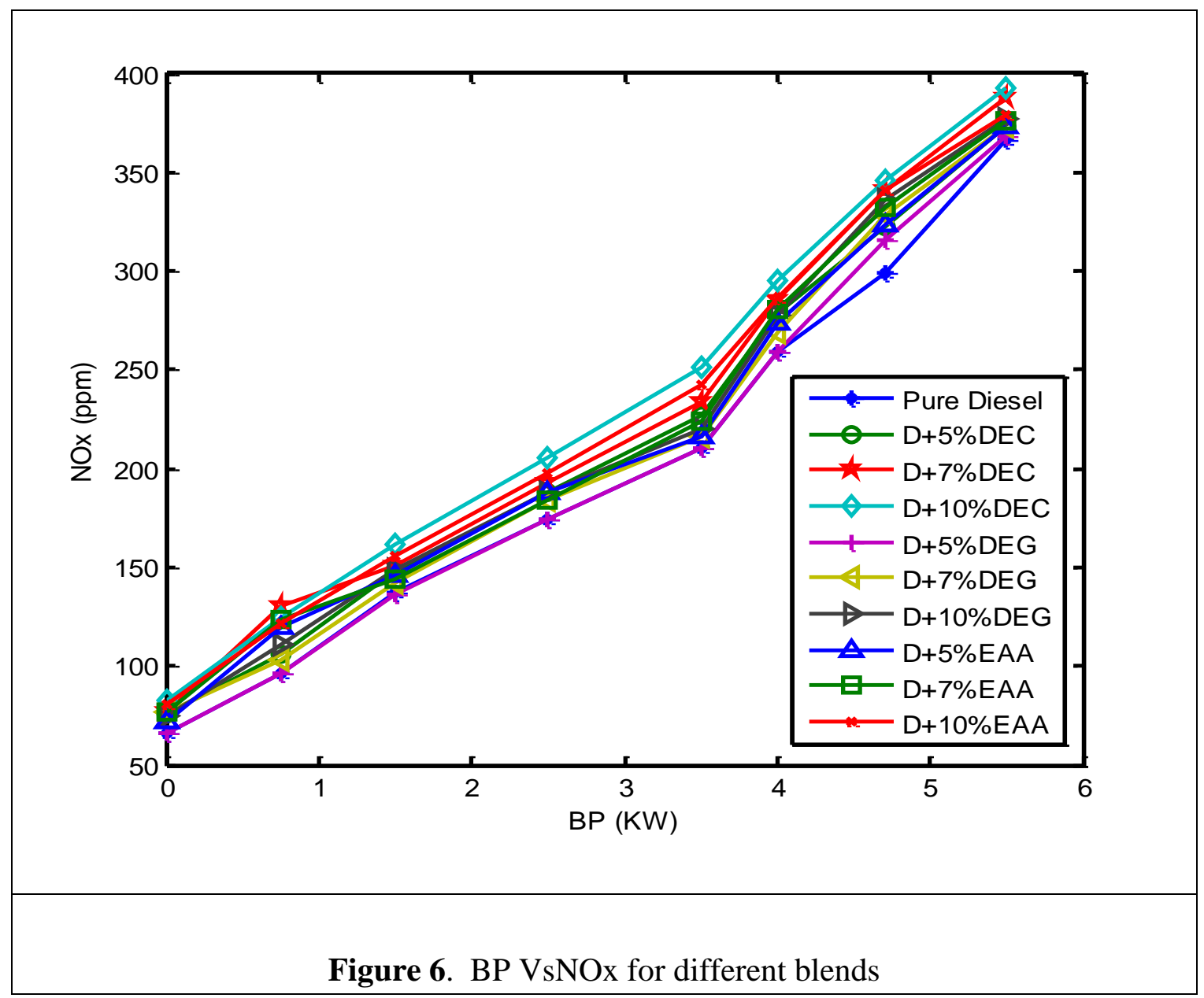

\subsubsection{Smoke emission}

Generally the smoke emission for diesel fuel increases rapidly at high loads. By using the oxygenated additive blends, the smoke emission can be reduced notablyat high loads.

There is a decrease in smoke emission with increasing percentage of oxygenates due to effective combustion. The $10 \%$ DEC blend shows good performance.From the figure 7, it is found that DEC blends shows better results compared to other blends and the smoke emission for diesel is 41.37\% opacity and for $10 \%$ DEC blend is $36.1 \%$ opacity. There is a decrease in smoke emission with increasing percentage of oxygenates due to efficient combustion. It is concluded 
that Diesel-10\% DEC blend is the best oxygenate blend compared with other percentage levels regarding smoke emissions.

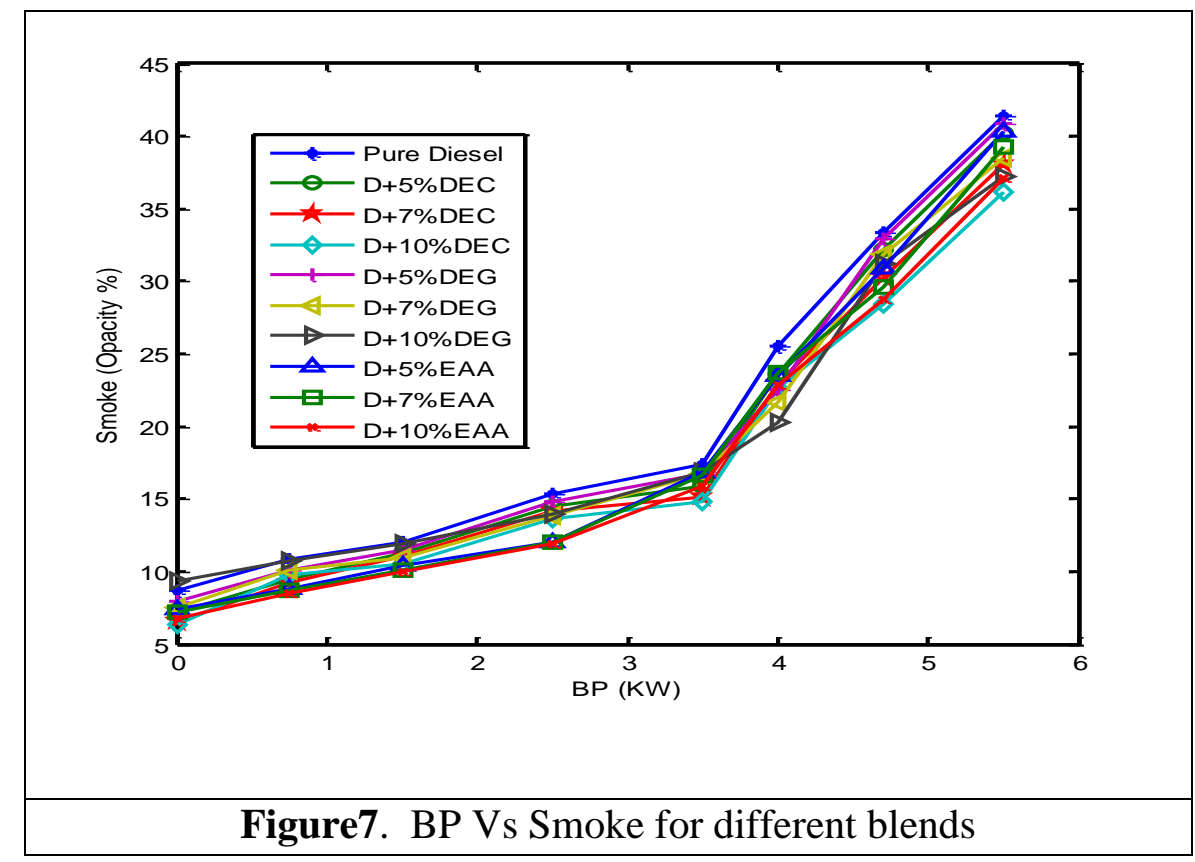

\section{Highlights:}

- The Brake Thermal Efficiency (BTE) of Diesel-10\% DEC is about 31.1\%, thus an increase of $3.9 \%$ is observed.

- All oxygenates show slightly lower Brake Specific Energy Consumption (BSEC) than pure diesel fuel. It is observed that, the BSEC of Diesel-10\% DEC is $12.1 \mathrm{MJ} / \mathrm{kWhr}$, thus saving $1.41 \mathrm{MJ} / \mathrm{kWhr}$.

- The CO emission of diesel is $2.68 \mathrm{~g} / \mathrm{KWhr}$ and the Diesel-10\% DEC blend is $1.96 \mathrm{~g} / \mathrm{KWhr}$.

- The HC emission for diesel is $0.33 \mathrm{~g} / \mathrm{kWhr}$ and for $10 \%$ DEC blend is $0.3 \mathrm{~g} / \mathrm{kW} \mathrm{hr}$.

- The Diesel-10\% DEC blend emits higher NOx emissions but as the Diesel-10\% DEC blend gives good outcomes in the other parameters discussed previously. For Diesel-10\% DEC blend the NOx emission is 393 ppm.

- It is found that DEC blends shows better results compared to other blends and the smoke emission for diesel is $41.37 \%$ opacity and for $10 \%$ DEC blend is $36.1 \%$ opacity.

\section{CONCLUSION}

Experiments were conducted in a four stroke single cylinder, naturally aspirated, water cooled, direct injection diesel engine to study the effects of diesel and blends of diesel with selected oxygenates using standard single injection. Three blends such as DEC, DEG and EAA with percentage by weight of, $5 \%, 7 \%$ and $10 \%$ in diesel were prepared and tested. The addition of oxygenated additives is one of the ways to enhance the physicochemical properties and ignition 
characteristics of a hydrocarbon fuel and it was found to be a proficient one. In this work, Engine performance and emission tests were conducted and the characteristics curves were analyzed for pure diesel and diesel with the addition of oxygenates in different proportions. The thermal efficiency of diesel with the addition of oxygenates is more than pure diesel at all loads. The Carbon monoxide, Hydro Carbon and NOx emission are lesser for diesel-oxygenate blends than pure diesel. The smoke opacity also decreases proportionately with diesel - oxygenate blends.

Based on the results the following conclusions were drawn:

1. The performance of CI Enginesincreases with the addition of oxygenates.

2. All three oxygenates are found to be effective at reducing smoke intensity with DEC being more effective than DEG and EAA.

3. $10 \% \mathrm{DEC}$ is the best oxygenated blend based on the results of pressure rise, heat release, thermal efficiency and emissions.

4. All the oxygenate affect $\mathrm{HC}, \mathrm{CO}$, smoke, $\mathrm{CO} 2$ and NOx emissions. The reduction of $\mathrm{HC}$ is $12 \%$, CO reduction is $26 \%$, Specific energy consumption reduction is $10 \%$ and the Brake thermal efficiency is increased by $3 \%$.

5. The $10 \%$ DEC blend is found to be good in reducing smoke level by $16 \%$.Oxygen content alone is not the only factor that influences smoke reduction in diesel engine combustion. Other property of the blending compounds like Cetane number also has a say in smoke reduction. The DEC has higher Cetane number.

6. Oxygenates are helping the premixed phase reactions to progress in a better way which leads to better combustion. The readily presented oxygen in the blends enhances the ignition process. All oxygenates show an increase of peak pressure by 2 bars to 3 bars compared to diesel. Premixed combustion is advanced and improves the heat release Peak pressure increase enable better combustion of fuel and heat release from the fuel.

\subsection{Scope for the future work}

1. The present investigation can be extended to multi cylinder CI engines.

2. The work can be extended to evaluate chemical effect of corrosion, deposit and wear of engine parts.

3. The investigation of $\mathrm{NOx}, \mathrm{CO}$ and $\mathrm{HC}$ emission over a wide range of blending level can be analyzed.

\section{REFERENCES}

[1] Natarajan, M., Frame, E., Naegeli, D., Asmus, T., Clark, W, Garbak, J, A. Manuel, D. González, Liney, E, Piel, W and Wallace, J, Oxygenates for Advanced PetroleumBased Diesel Fuels: Part 1. Screening and Selection Methodology for the Oxygenates, (2001),SAE Technical Paper 2001-01-3631.

[2] Kumaresan, M., Devaradjane, G,Effect of two-springs split injection on the performance and emission characteristics of diesel-oxygenated blends in a DI diesel 
engine. Indian Journal of Engineering and Materials Sciences, Vol.19 (6) (2012), 411416.

[3] AbhijitKulkarni., GauriSalvi., MandarGophane., Ashok,B, Performance and Emission Analysis of Diesel Engine Using Blended Fuel and Study of Emulsion. International Journal of Applied Engineering Research, Vol. 8, No. 17 (2013), 2343-2346.

[4] Singh,S., Kumar,A., Mahla, S. K.., Batth, G. S, Experimental study on emission analysis of oxygenated fuels dimethyl carbonate (DMC) and dibutyl maleate (DBM) in a CI engine. International Journal of Research in Engineering and Technology, vol. 2, Issue 10 (2013), 158-162.

[5] Venkatraman,M., Abhijetdey., Ajay kumar., Deepak kumar, Experimental and Theoretical Investigation on Performance and Emission Characteristics of Diesel Fuel Blends. International Journal of Chemical Sciences. 14(4) (2016), 2967-2972.

[6] Upatnieks, A., Mueller, C, Investigation of the Relationship between DI Diesel Combustion Processes and Engine-Out Soot Using an Oxygenated Fuel, (2004), SAE Technical Paper 2004-01-1400.

[7] Guo, H., Zheng, L, Effects of a Blend of Eethanol and Ethylene Glycol Dimethyl Ether on Fuel Properties and Engine Performances When Used as Clean Diesel Fuel Additive, (2014),SAE Technical Paper, 2014-01-2771.

[8] T. Nibin, A. P. Sathiyagnanam, S. Sivaprakasamand C. G. Saravanan, Investigation on Emission Characteristics of a Diesel Engine Using Oxygenated Fuel Additive,Journal of Institution of Engineers (India), Vol. 86 (2005), 51-54.

[9] Y. Ren et al, Effect of the Addition of Diglyme in Diesel Fuel on Combustion and Emissions in a Compression- Ignition Engine, Energy \& Fuels,(2007), 2573-2583.

[10] J. Wang, F. Wu, J. Xiao, Oxygenated blend design and its effects on reducing diesel particulate emissions, Fuel, 88 (10) (2009), 2037-2045.

[11] P. Baskar, K. Nanthagopal and T. Elango, The effect of two oxygenates on diesel engine emissions, ARPN Journal of Engineering and Applied Sciences, 6 (3) (2011), $55-60$.

[12] K. I. Burshaid A, M.A. Hamdan, The Reduction of Soot Formation from Fuels Using Oxygenates Additives,Fuel, 88 (10) (2009), 2037-2045.

[13] G. Yanfeng, L. Shenghua, G. Hejun, H. Tiegang, Z. Longbao, A new diesel oxygenate additive and its effects on engine combustion and emissions, Applied Thermal Engineering, 27 (1) (2007), 202-207.

[14] Y. WANG, Y. LIU, An Oxygenating Additive for Reducing the Emission of Diesel Engine, Bioinformatics and Biomedical Engineering, The 2nd International Conference (2008), 3931 - 3933.

[15] H. H. Masjuki, M.A. Kalam, M. Syazly, T.M.I Mahlia, A.H. Rahman, M. Redzuan, M. Varman R. Saidur, and Y.H. Yau, Experimental Evaluation of an Unmodified Diesel Engine using Biodiesel with Fuel Additive, Strategic Technology Conference, The 1st International Forum (2006), 96 - 99. 
[16] SadhikBasha, J. and Anand, R.B, Applications of nanoparticle/nanofluid in compression ignition engines - a case study, International Journal of Applied Engineering Research, Vol. 5(2010), 697-708.

[17] Mohamed Yusuf Ali, M.Masood, S.N.Mehdi , A CFD Combustion analysis of Hydrogen -Biodiesel dual fuelsystem, World Applied Science Journal 9 (2) (2010), 144-150.

[18] K. Kannan and M. Udayakumar, NOx and HC Emission Control Using Water Emulsified Diesel in Single Cylinder Diesel Engine, ARPN Journal of Engineering and Applied Sciences, Vol. 4, No. 8, (2009), ISSN 1819-6608.

[19] R. Bhoobathi, ShaikAmjad, and Dr. R. Rudramoorthy, Diesel Engine Combustion Simulation using Computational Fluid Dynamics, Process of International Conference on Advances in Mechanical Engineering (2010), 18-22.

[20] T.S. Strauss, G.W. Schweimer and U. Ritscher, Combustion in a Swirl chamber Diesel engine Simulation by Computation of Fluid Dynamics,SAE Trans. 104, Section: Journal of Engines (1995), 519-530.

[21] Y. Kidoguchi, M. Sanda and K. Miwa, Experimental and theoretical optimization of combustion chamber and fuel distribution for the Low Emission Direct - Injection Diesel Engines, Engg for Gas turbines \& Power(2003), Vol.125/351.

[22] Reitz R.D. andRootland C.J., Development and testing of diesel engine CFD model,Progess.Combustion.Science, vol.21 (1995), 173-196.

[23] Yu Li, Jinke Gong, Wenhua Yuan, Experimental investigation on combustion, performance, and emissions characteristics of butanol as an oxygenate in a spark ignition engine,Advances in Mechanical Engineering (2017), Vol. 9(2) 1-13.

[24] Amith Kishore Pandian ,Dinesh Babu Munuswamy, Influence of an oxygenated additive on emission of an engine fueled with neat biodiesel, Pet. Sci. (2017) 14:791797.

\section{Biography :}

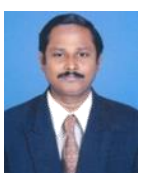

Dr.S.Sundarapandian received his Ph.D in IC Engine Combustion \& Alternative Fuels from Anna University, Chennai, Tamil Nadu. He is currently working as a Professor in the Automobile Engineering Department at Easwari Engineering College, Chennai, Tamil Nadu, India, where he is focused on teaching and research in IC Engines. He has experience in industry for 5 years and teaching experience of more than 20 years. He has 15 research publications in International and 5 in National Journals and 15 conferences both National and International. He is a reviewer of Energy; scientific journal international.He has produced 2 Ph.D Scholars and Eight 
$\mathrm{Ph}$. Dscholars are doing their Ph.D work under his guidance.His research interests include IC Engines and Alternative Fuels. He is a Life member of SAE, IE, Combustion Institute and ISTE.

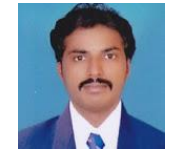

Prof.B.Parthasarathi received his Master Degree in Engineering Design from Anna University, Chennai, Tamil Nadu. He is an Associate Professor in the Mechanical Engineering Department at Arunachala College of Engineering for Women, Nagercoil, Kanyakumari(Dt), Tamil Nadu. He has the teaching experience of more than 14 years. He published his research articles in International Journals and in International and National conferences. His research interests include IC Engines design, Alternative Fuels and Composite materials. He is a Life member of Indian Society for Technical Education. 